\title{
The interaction between different types of activated RAW 264.7 cells and macrophage inflammatory protein- 1 alpha
}

Zhongshi He ${ }^{1,2}$, Hui Zhang ${ }^{1,2}$, Chunxu Yang ${ }^{1,2}$, Yajuan Zhou ${ }^{1,2}$, Yong Zhou ${ }^{1,2}$, Guang Han², Ling Xia', Wen Ouyang ${ }^{1}$, Fuxiang Zhou', Yunfeng Zhou ${ }^{1}$ and Conghua Xie ${ }^{1 *}$

\begin{abstract}
Background: Two major ways of macrophage (M $\Phi)$ activation can occur in radiation-induced pulmonary injury (RPI): classical and alternative $M \Phi$ activation, which play important roles in the pathogenesis of RPI. M $\Phi$ can

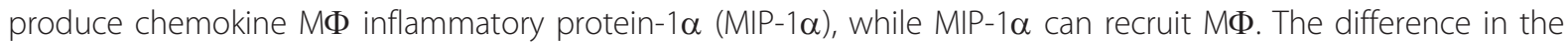
chemotactic ability of MIP-1 $\alpha$ toward distinct activated $M \Phi$ is unclear. We speculated that there has been important interaction of MIP-1 $\alpha$ with different activated MФ, which might contribute to the pathogenesis of RPI.
\end{abstract}

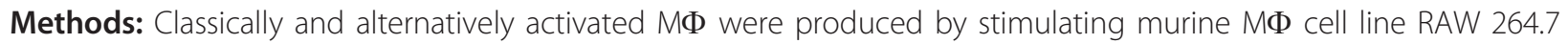
cells with three different stimuli (LPS, IL-4 and IL-13); Then we used recombinant MIP-1 $\alpha$ to attract two types of activated $М \Phi$. In addition, we measured the ability of two types of activated $M \Phi$ to produce MIP-1 $\alpha$ at the protein or mRNA level.

Results: Chemotactic ability of recombinant MIP-1 $\alpha$ toward IL-13-treated MФ was the strongest, was moderate for IL-4-treated $M \Phi$, and was weakest for LPS-stimulated $M \Phi(p<0.01)$. The ability of LPS-stimulated M $\Phi$ to secrete MIP-1 $\alpha$ was significantly stronger than that of IL-4-treated or IL-13-treated $M \Phi(p<0.01)$. The ability of LPS-

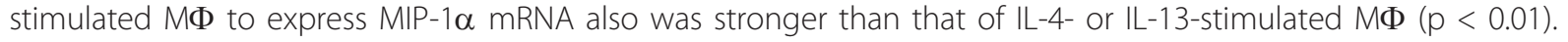

Conclusions: The chemotactic ability of MIP-1 $\alpha$ toward alternatively activated $M \Phi(M 2)$ was significantly greater

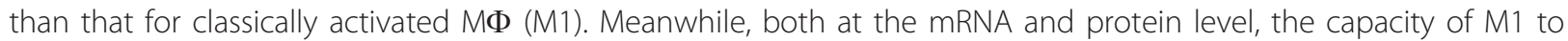
produce MIP-1 $\alpha$ is better than that of M2. Thus, chemokine MIP-1 $\alpha$ may play an important role in modulating the transition from radiation pneumonitis to pulmonary fibrosis in vivo, through the different chemotactic affinity for $\mathrm{M} 1$ and M2.

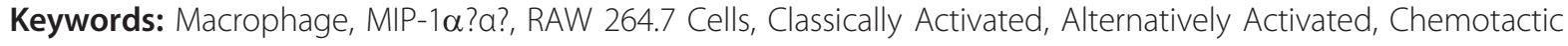
Ability

\section{Background}

Radiation-induced pulmonary injury (RPI) can occur during radiotherapy for thoracic cancer and limits the radiation dose that can be applied. Although the histopathological features of RPI have been well documented, its pathogenesis has not been elucidated. Many types of inflammatory cells are involved in RPI, but pulmonary

\footnotetext{
* Correspondence: chxie_65@hotmail.com

'Department of Radiation and Medical Oncology, Zhongnan Hospital, Wuhan University, 169, Donghu Road, Wuchang District, Wuhan, Hubei 430071, P.R. China

Full list of author information is available at the end of the article
}

macrophages $(\mathrm{M} \Phi)$ are the most prominent [1]. Different populations of activated $M \Phi$ can arise in response to distinct stimuli. When stimulated by lipopolysaccharide (LPS) and/or IFN- $\gamma$, the classically activated MФ (M1) is generated, which secretes high levels of proinflammatory cytokines and mediators [2], and expresses inducible NO synthase (iNOS) [3]. M1 may enhance the microbicidal activity of $\mathrm{M} \Phi$ and is closely associated with radiation pneumonitis. The amount of $М \Phi$ in the lung increases quickly after irradiation [2]. The second population of activated $M \Phi$ is alternatively activated MФ (M2) that arises in the presence of the cytokines 
IL-4, IL-13, glucocorticoids, or TGF- $\beta$. M2 upregulates the expression of mannose receptors [4], decreases the antigen-presenting capability of $\mathrm{M} \Phi$, and shows high arginase 1 activity [3]. Arginase 1 can contribute to the production of ECM by catalyzing the formation of polyamines and collagen, overexpression of which improves pulmonary fibrosis. Excessive IL-4 and the related M2 have been observed in radiation pulmonary fibrosis (RPF) [2].

A variety of inflammatory cells play significant roles in RPI, and chemokines also have non-redundant roles of recruiting $M \Phi$ and other effector cells to the sites of inflammatory injury [4]. Chemokines, especially macrophage inflammatory protein-1 $\alpha$ (MIP- $1 \alpha$, also known as CCL3) and related CC-chemokines, act as signal transducers in inflammatory injury, and perform important regulatory functions [5]. MIP-1 $\alpha$ is thought to arise mainly from $M \Phi$ and epithelial cells in the lung. Different activated $М \Phi$ have different behavior related to MIP- $1 \alpha$ secretion. M1 stimulated by LPS and IFN- $\gamma$ promotes MIP-1a-generation, while IL-4 and IL-10 inhibit MIP-1a production of MФ induced by LPS or IL- $1 \beta$ $[6,7]$. MIP-1 $\alpha$, which possesses strong chemotactic affinity for $M \Phi$, is a critical $M \Phi$ chemoattractant in murine wound repair $[8,9]$.

The hypothesis of a perpetual cascade of cytokines leading to RPI is a reasonable explanation [10]. However, the hypothesis does not specify which cell or cytokine dominates in the cascade response. The mechanism of the transition from radiation pneumonitis to RPF also is unknown, as is whether the chemotactic affinity of MIP$1 \alpha$ is different for distinct activated $М \Phi$. We speculate that MIP- $1 \alpha$ arises mainly from M1, while its chemotactic affinity toward M2 is stronger than for M1. The interaction between MIP- $1 \alpha$ and MФ in different activated states may play a crucial role in regulating the transition from radiation pneumonitis to RPF. By constructing classically and alternatively activated models of $M \Phi$ induced by different stimuli (LPS, IL-4 and IL-13), the interaction between MIP-1 $\alpha$ and different activated $\mathrm{M} \Phi$ was studied in vitro to investigate the pathogenesis of RPI.

\section{Materials and methods \\ Macrophage culture}

The murine MФ cell line RAW 264.7 was obtained from the China Center for Type Culture Collection (CCTCC) at Wuhan University, and grown in DMEM supplemented with $10 \%$ heated-inactivated FCS, $2 \mathrm{mmol} / \mathrm{L} \mathrm{L}$-glutamine, and $100 \mathrm{U} / \mathrm{mL}$ penicillin/streptomycin (GIBCO) at $37^{\circ} \mathrm{C}$ in a humidified incubator of $5 \% \mathrm{CO}_{2}$. For some experiments, cells were starved, which means that cells were washed with phosphate-buffered saline (PBS) and incubated in DMEM supplemented with $100 \mathrm{U} / \mathrm{mL}$ penicillin/streptomycin for $12 \mathrm{~h}$, but without $10 \%$ heated-inactivated FCS or $2 \mathrm{mmol} / \mathrm{L}$ L-glutamine. Cells between passages 5 and 20 were used in this study.

\section{Experimental design}

Cells were plated in 24-well plates (for nitrite $\left[\mathrm{NO}_{2}{ }^{-}\right]$or urea measurements) at $5 \times 10^{5}$ cells/well. When the cells fully adhered after starvation for 12 hours, they were exposed to $30 \mathrm{ng} / \mathrm{mL}$ LPS (Sigma), IL-4 (PeproTech), or IL-13 (PeproTech), respectively. At the scheduled time points (see Figures 1A, 2A, C), the supernatant from the cells stimulated by LPS was
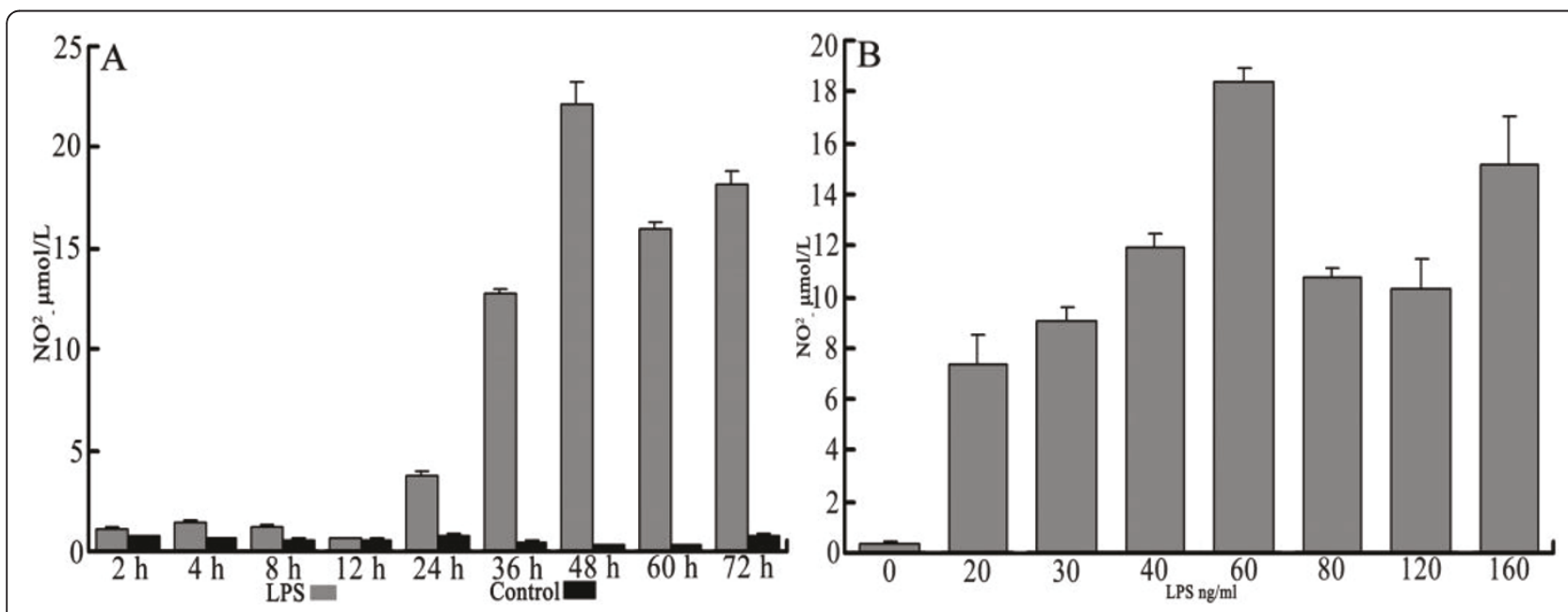

Figure 1 NO production of RAW 264.7 cells stimulated by LPS. A. RAW cells were exposed to either $0 \mathrm{ng} / \mathrm{mL}$ or $30 \mathrm{ng} / \mathrm{mL} L P S$. At scheduled time points, the cell supernatant was collected for determination of $\mathrm{NO}_{2}{ }^{-}$with Griess reagent. B. RAW cells were exposed to LPS for $48 \mathrm{~h}$ at different concentrations, then $\mathrm{NO}_{2}{ }^{-}$was measured in the same way as in A. Values are averages $\pm \mathrm{SD}$ of two independent experiments each done in triplicates; ${ }^{* *}$ indicates $p<0.01$, (one way ANOVA). 


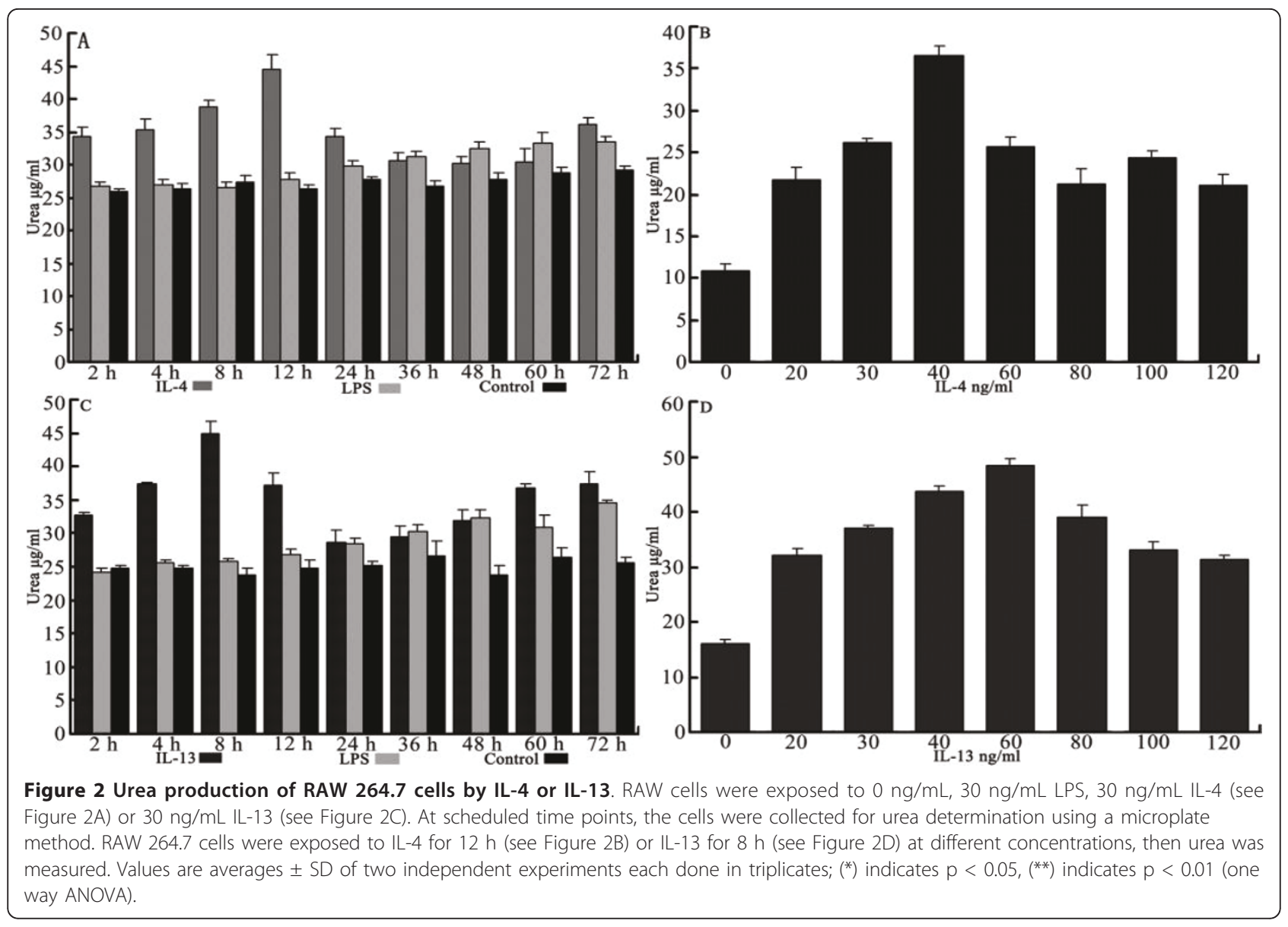

collected for $\mathrm{NO}_{2}{ }^{-}$measurement using the colorimetric Griess reaction [11]; cells stimulated by IL-4 or IL-13 were gathered to for urea measurement using a microplate method [12]. The best incubation time was determined by the preceding time points. Cells were plated and starved in the same way again, then exposed to LPS, IL-4, or IL-13 at seven different concentrations (see Figures 1B, 2B, D). After incubation, measurement of $\mathrm{NO}^{-}$was done for LPS-stimulated samples and measurement of urea was done for IL-4- or IL-13-treated samples to determine the best concentration for stimulus.

Cells were then plated in a culture flask at $5 \times 10^{5}$ cells/ $\mathrm{mL} \times 6 \mathrm{~mL}$, for the chemotaxis assay, or in $60-\mathrm{mm}$ dishes at $5 \times 10^{5}$ cells $/ \mathrm{mL} \times 3 \mathrm{~mL}$ for measurement of protein expression of MIP-1 $\alpha$ from the cell supernatant, or for detection of MIP-1 $\alpha$ mRNA in the cells. Optimal concentrations of LPS, IL-4, or IL-13, as determined by the earlier experiments, were used to determine the best times.

\section{Measurement of nitric oxide}

The production of $\mathrm{NO}$ was measured by determining $\mathrm{NO}_{2}{ }^{-}$in the culture supernatants using the colorimetric
Griess reaction. Aliquots $(60 \mu \mathrm{L})$ of cell supernatant were combined with an equal volume of Griess reagent [1\% sulfanilamide (Alfa Aesar)/0.1\% N-(1-napthyl) ethylenediamine (International Laboratory USA) - each in $2.5 \% \mathrm{H}_{3} \mathrm{PO}_{4}$ ] in a 96-well plate at room temperature for $10 \mathrm{~min}$, and the absorbance at $550 \mathrm{~nm}$ was measured with a Multiscan plate reader (Genios, Tencan). Absorbance measurements were averaged and converted to $\mu \mathrm{mol} / \mathrm{L}$ of $\mathrm{NO}_{2}{ }^{-}$per well using a standard curve of sodium nitrite.

\section{Determination of arginase activity}

Arginase activity was determined according to a microplate method with slight modification. After incubation for the scheduled time, the cells were rinsed with PBS, then lysed with $300 \mu \mathrm{L}$ of $0.5 \%$ Triton X-100 that contained protease inhibitors (Sigma). After shaking for 30 min at room temperature, the lysate was mixed with $400 \mu \mathrm{L}$ of $25 \mathrm{mmol} / \mathrm{L}$ Tris-HCL (pH 7.4) and $100 \mu \mathrm{L}$ of $10 \mathrm{mmol} / \mathrm{L} \mathrm{MnCl}_{2}$. The arginase was activated by heating for $10 \mathrm{~min}$ at $56^{\circ} \mathrm{C}$. Arginine hydrolysis to urea was conducted by addition of $50 \mu \mathrm{L}$ of $0.5 \mathrm{~mol} / \mathrm{L} \mathrm{L}$-arginine (pH 9.7) to $50 \mu \mathrm{L}$ of the activated lysate, followed by 
incubation at $37^{\circ} \mathrm{C}$ for $60 \mathrm{~min}$. The reaction was stopped with $800 \mu \mathrm{L}$ of $\mathrm{H}_{2} \mathrm{SO}_{4}(96 \%) / \mathrm{H}_{3} \mathrm{PO}_{4}(85 \%) / \mathrm{H}_{2} \mathrm{O}$ $(1 / 3 / 7, \mathrm{v} / \mathrm{v} / \mathrm{v})$. Urea concentration was measured at 550 $\mathrm{nm}$ after addition of $50 \mu \mathrm{L}$ of $9 \%(\mathrm{w} / \mathrm{v})$ a-isonitrosopropiophenone (Tokyo Chemical Industry Co. LTD) dissolved in $100 \%$ ethanol and heating at $100^{\circ} \mathrm{C}$ for $45 \mathrm{~min}$. A standard curve was created using two-fold dilutions of urea $(1.25 \mu \mathrm{g} / \mathrm{mL}$ to $640 \mu \mathrm{g} / \mathrm{mL})$ following by mixing with the stop reagent and then heating.

\section{Chemotaxis assay}

The ability of rMIP-1 $\alpha$ (PeproTech) to promote MФ chemotaxis was measured with a 24-well Transwell chamber (Sigma). When the $М \Phi$ in the culture flask was stimulated, it was washed twice with PBS and suspended in DMEM at a concentration of $5 \times 10^{5}$ cells/ $\mathrm{mL}$. A series of MIP-1 $\alpha$ or DMEM alone (negative control) (see Figure 3) were placed in the bottom wells of the chemotaxis chamber and 8- $\mu \mathrm{m}$ thick polycarbonate filters were placed on top of the wells. MФ suspensions $(200 \mu \mathrm{L})$ were placed on the top of wells and the chamber was incubated at $37^{\circ} \mathrm{C}$ for $120 \mathrm{~min}$. The filters were removed and nonmigrating cells (facing the top wells) were gently washed off with PBS and then air-dried. After staining $\mathrm{M} \Phi$ with $150 \mathrm{uL}$ of crystal violet, cell counts were determined using a light microscope to compare the strength of the chemotactic affinity.

\section{MIP-1 $\alpha$ measurement by ELISA}

Extracellular immunoreactive MIP-1 $\alpha$ was measured by ELISA using a commercial kit (R\&D) according to the manufacturer's instructions. Sample absorbance was

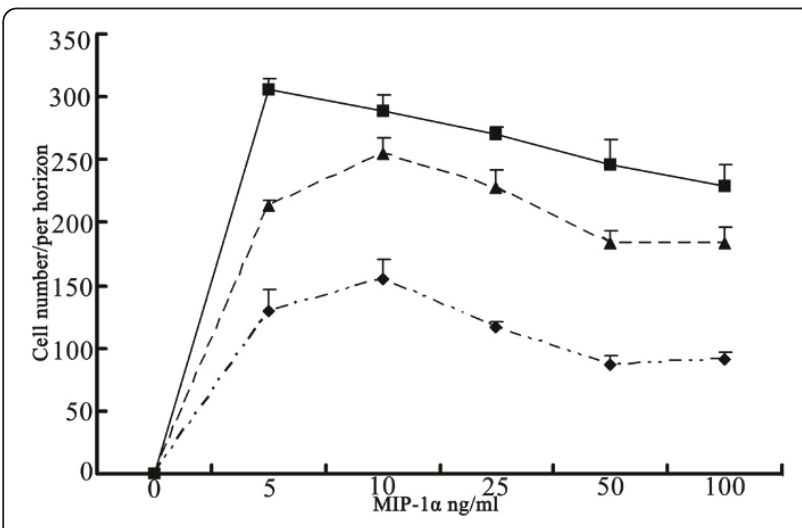

Figure 3 Recombinant MIP- $1 \alpha$ as a potent chemoattractant for $\mathbf{M} \Phi$ in vitro. Cells were exposed to $60 \mathrm{ng} / \mathrm{mL}$ LPS for $48 \mathrm{~h}, 40 \mathrm{ng} /$ $\mathrm{mL} I \mathrm{~L}-4$ for $12 \mathrm{~h}$, or $60 \mathrm{ng} / \mathrm{mL} \mathrm{IL}-13$ for $8 \mathrm{~h}$, followed by cell collection. M $\Phi$ chemotaxis was measured in a Transwell chamber with rMIP- $1 \alpha$ at several concentrations. Results are expressed as cell number/horizon under a light microscope (250 times) Values are averages \pm SD done in triplicates; Significant difference $(p<0.01)$ of chemotactic ability was obvious for different activated states of $M \Phi$ (one way ANOVA). measured with a Multiscan plate reader (Genios, Tencan) at a wavelength of $450 \mathrm{~nm}$. The sample concentration was measured using a standard curve.

\section{Real-time quantitative PCR of MIP-1 $\alpha$}

Total cellular RNA was extracted using Trizol according to the manufacturer's instructions. Then RNA was reverse-transcripted into cDNA using reverse-transcriptase (Toyobo). For amplification by PCR, the forward primer for MIP- $1 \alpha$ was CTCCCAGCCAGGTGTCATT, and the reverse primer was GGCATTCAGTTCCAGGTCAG. The forward primer for $\beta$-actin was CCGTGAAAAGATGACCCAG, and the reverse primer was TAGCCACGCTCGGTCAGG. The PCR conditions were as follows: $95^{\circ} \mathrm{C}, 45 \mathrm{sec} ; 60^{\circ} \mathrm{C}, 15 \mathrm{sec} ; 72^{\circ} \mathrm{C}, 45 \mathrm{sec}$ for 40 cycles. Amplification was terminated by $10 \mathrm{~min}$ at $72^{\circ} \mathrm{C}$. For data analysis, the comparative threshold cycle (CT) value for $\beta$-actin was used to normalize loading variations in the real-time PCRs. $\Delta \Delta C \mathrm{CT}$ value then was obtained by subtracting the control $\Delta \mathrm{CT}$ values from the corresponding experimental $\Delta \mathrm{CT}$ values. The $\Delta \Delta \mathrm{CT}$ values were compared with the control by raising two to the $\Delta \Delta C T$ power.

\section{Statistical analysis}

Statistical analyses of data were conducted using oneway analysis of variance (ANOVA). Statistical significance was established at $\mathrm{p}<0.05$. The software used for statistical analysis was SPSS 13.0 (SPSS, Inc., Chicago, IL).

\section{Results}

\section{Expression of macrophage enzyme activity}

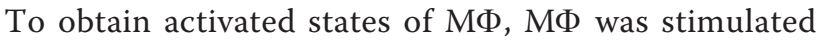
by LPS, IL-4, and IL-13, and then the activated states were evaluated by measuring iNOS and arginase activity. M1 induced by LPS expressed specific iNOS activity, while M2 stimulated by IL-4 or IL-13 showed particular arginase 1 activity. Therefore, the magnitude of iNOS or arginase activity was chosen to reflect the strength of classically or alternatively activated states of MФ.

Experimental results demonstrated that, compared with iNOS activity of quiescent $M \Phi$, the activity in $M \Phi$ increased significantly after M $\Phi$ was stimulated by LPS $(30 \mathrm{ng} / \mathrm{mL})$ for 12 hours $(\mathrm{p}<0.01)$, and peaked at 48 hours (see Figure 1A). When stimulated with various concentrations for a fixed time ( $48 \mathrm{~h}), \mathrm{M} \Phi$ induced by $60 \mathrm{ng} / \mathrm{mL}$ LPS expressed the greatest iNOS activity (see Figure 1B). Compared with arginase activity of quiescent and LPS-stimulated $M \Phi$, arginase activity was increased significantly when $М \Phi$ was treated by IL- $4(30 \mathrm{ng} / \mathrm{mL})$ within 24 hours $(\mathrm{p}<0.01)$ or by IL-13 $(30 \mathrm{ng} / \mathrm{mL})$ within 12 hours $(\mathrm{p}<0.01)$. The quiescent and LPS-stimulated $M \Phi$ also expressed arginase activity. In 
comparison with quiescent $M \Phi$, the $М \Phi$ stimulated by LPS for 36 hours resulted in an increase of arginase expression ( $p>0.05$ ), but significantly less than the activity resulting from $М \Phi$ stimulated by IL-4 within 24 hours, or MФ stimulated by IL-13 within 12 hours (see Figures 2A, C). When stimulated with different concentrations at a fixed time, МФ induced by $40 \mathrm{ng} / \mathrm{mL}$ IL-4 or $60 \mathrm{ng} / \mathrm{mL}$ IL-13 showed the greatest arginase activity (see Figures 2B, D). Thus, the optimal conditions were stimulation of classically activated MФ with $60 \mathrm{ng} / \mathrm{mL}$ LPS for 48 hours, stimulation of alternatively activated MФ with $40 \mathrm{ng} / \mathrm{mL}$ IL4 for 12 hours, and stimulation of alternatively activated MФ with $60 \mathrm{ng} / \mathrm{ml}$ IL-13 for 8 hours.

These results provide further information about the factors involved in arginase activity from alternative macrophages. In contrast with a previous report of urea production from different activated $M \Phi$ [10], the present results showed that urea production of the cells produced a bell-shaped response with both IL-4 and IL13 at different stimulation times or concentrations (see Figure 2). This difference was attributed to the experimental conditions that were repeatedly explored in the pre-experimental phase, and represents a change in arginase activity of RAW 264.7, indicating that stimulation time and concentration of the stimulus both significantly affect enzyme activity.

\section{Chemotactic ability of MIP- $1 \alpha$ toward activated macrophages}

A difference in the chemotactic ability of MIP-1 $\alpha$ for different activated $М \Phi$ was verified. This difference was reflected in two ways. First, chemotactic ability was distinct for different activated states of MФ ( $\mathrm{p}<0.01)$. Chemotactic ability of MIP- $1 \alpha$ toward IL-13-treated MФ was the strongest, was moderate for IL-4-treated M $\Phi$, and was weakest for LPS-stimulated MФ. Second, the peak concentration of MIP- $1 \alpha$ for different activated MФ also was different, with a peak concentration for IL-13-stimulated $\mathrm{M} \Phi$ of $5 \mathrm{ng} / \mathrm{mL}$, but a peak concentration for IL-4and LPS-stimulated MФ of $10 \mathrm{ng} / \mathrm{mL}$ (see Figure 3).

\section{Comparison of macrophages producing MIP- $1 \alpha$}

The capacity of MIP-1 $\alpha$ production for different acti-

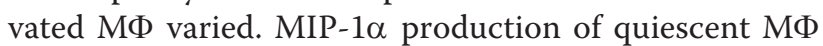
at different time points was not statistical different $(\mathrm{p}>$ 0.05 ) at the mRNA or protein level. At the protein level, MIP-1 $\alpha$ expression from cell supernatants was determined by ELISA. The ability of LPS-stimulated MФ to secrete MIP-1 $\alpha$ was significantly stronger than that of IL-4-treated or IL-13-treated MФ ( $\mathrm{p}<0.01)$. Compared with untreated quiescent $M \Phi$, the $M \Phi$ stimulated by IL4 or IL-13 produced lower levels of MIP-1 $\alpha$ secretion (see Figure 4A). At the mRNA level, MIP-1 $\alpha$ expression from cells was determined by RT-PCR. The ability of LPS-stimulated MФ to express MIP- $1 \alpha$ mRNA also was stronger than that of IL-4- or IL-13-stimulated MФ ( $\mathrm{p}<$ 0.01 ) (see Figure 4B). Therefore, we conclude that at the level of either protein or mRNA, M $\Phi$ stimulated by LPS was able to express MIP-1 $\alpha$ significantly better than MФ stimulated by IL-4 or IL-13.

\section{Discussion}

The interaction between chemokines and macrophages is complex, which significantly affects macrophage biological

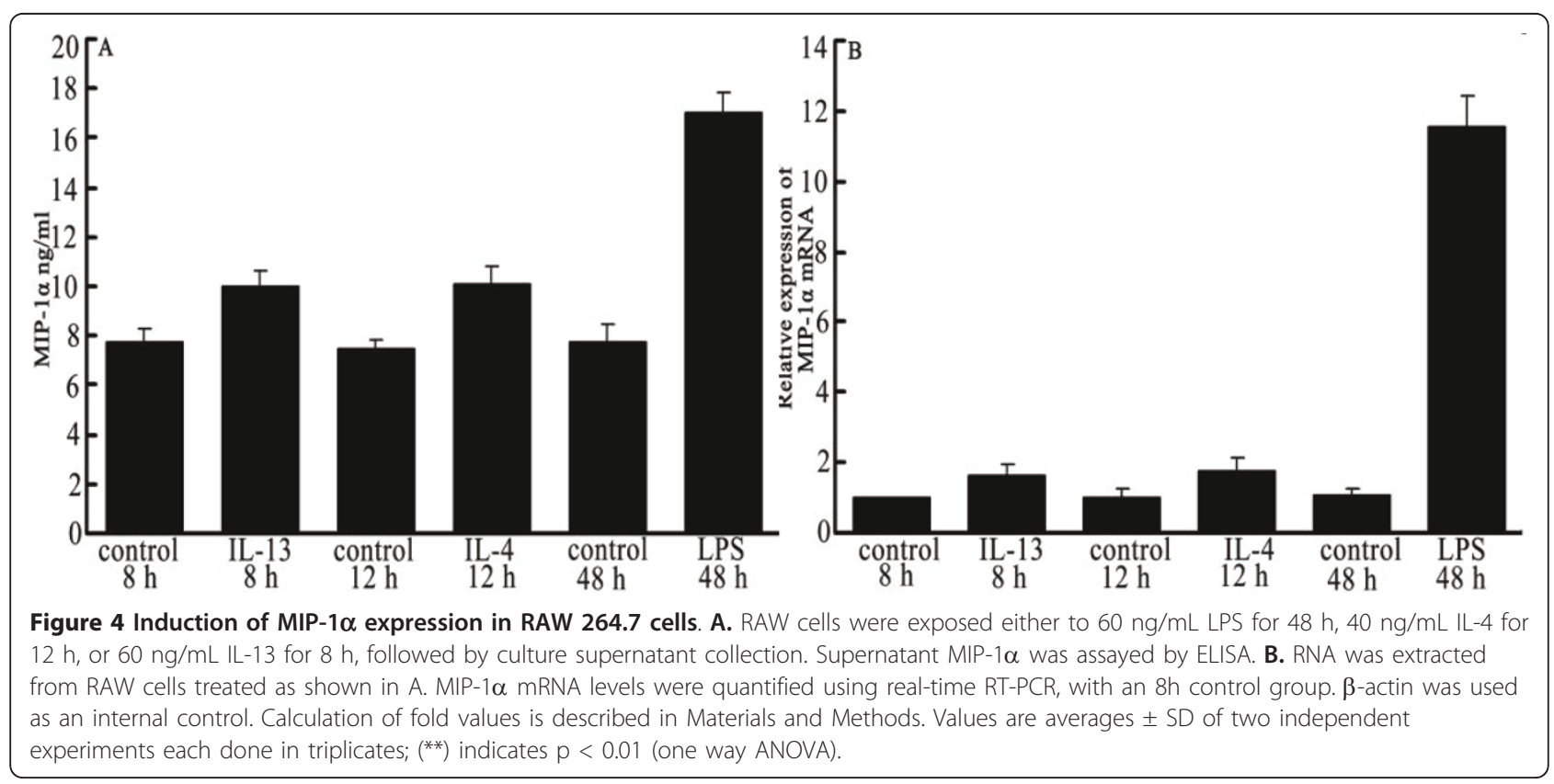


activity. Through experiments in vitro, we discovered that the chemotactic ability of MIP- $1 \alpha$ toward M2 is significantly stronger than that for M1, while the capacity of M1 to produce MIP- $1 \alpha$ is better than that of M2.

However, little information existed about whether a difference exists in the chemotactic ability of MIP- $1 \alpha$ for different activated МФ. Several groups have reported there is a preferential attraction of certain subsets of lymphocytes by human MIP-1 $\alpha$ [13,14], MIP-1 $\alpha$ is a potent chemoattractant for $\mathrm{M} \Phi$. By chemokine binding to cell surface CC chemokine receptors of $М \Phi$, which belong to the G-protein-coupled receptor superfamily, the G-protein complex can induce $\mathrm{Ca}^{2+}$ from extracellular and smooth endoplasmic reticulum influx into cytoplasm [15]. An increase in $\mathrm{Ca}^{2+}$ in cytoplasm is necessary for МФ migration. The results of our experiments indicate that the chemotactic ability of MIP- $1 \alpha$ for M2 is significantly stronger than that for M1. LPS could rapidly inhibit expression of CC chemokine receptors by reduction of CCR 1 mRNA levels in monocytes [16]. A distinct stimulus leading to differences in the properties and numbers of $\mathrm{CC}$ chemokine receptors in activated МФs may contribute to the chemotactic ability disparity of MIP-1 $\alpha$ for activated MФ.

And there are mininal effective and maximal concentrations for human MIP-1 $1 \alpha$ 's chemotaxis. Human MIP$1 \alpha$ was found to chemoattract NK cells in vitro, and maximal activity was obtained at a concentration of $100-1000 \mathrm{ng} / \mathrm{ml}[17,18]$. Our results may confirm a similar conclusion. At the concentration range of 8-18 $\mathrm{ng} / \mathrm{ml}$, MIP-l $\alpha$ shows maximum chemotactic activity for different activated macrophages.

Many cells, especially $\mathrm{M} \Phi$, can express low levels of MIP- $1 \alpha$ constitutively, which can be induced or inhibited by regulators. The same regulator may exert an opposite effect on different cells. For example, IL-4 and IL-10 inhibit MIP-1 $\alpha$ production of MФ stimulated by LPS or IL- $1 \beta$, while IL- 4 , IL-10, INF- $\gamma$, and IL- $1 \beta$ all induce vascular smooth muscle cells to produce MIP-1 $\alpha$ [19]. Our experiments indicated that, at the mRNA and protein level, the ability of MФ stimulated by LPS to secrete MIP-1a is significantly greater than that of MФ stimulated by IL-4 or IL-13. Thus, the ability of M1 to produce MIP- $1 \alpha$ is better than that of M2. The ability of M2 induced by IL-4 or IL-13 to produce MIP- $1 \alpha$ is only slightly enhanced when compared to the control group, which seems to contradict IL-4 inhibition of LPS-induced MIP-1 $\alpha$ secretion. This phenomenon may result from a difference in the original activated states of $\mathrm{M} \Phi$.

Different activated MФ in RPI are induced by distinct cytokines generated by damaged cells after $\gamma$-ray irradiation of the lung. Classical activation of macrophages was originally reported to require both TNF- $\alpha$ and IFN- $\gamma$
[20]. Bacterial endotoxin LPS was chosen as a stimulus for murine MФ cell line RAW 264.7 cells to generate M1 in this study because LPS (a Toll-like receptor agonist) stimulates $М \Phi$ in an autocrine manner to induce both TNF and IFN- $\beta$ and activate MФ [21]. IFN- $\gamma$, LPS, and IFN- $\gamma+$ LPS are weak, moderate, and strong inducers of iNOS activity, respectively, in in vitro experiments [22], so single stimulus LPS was best at inducing M1, when compared to other single inducers.

The M2 designation encompasses cells with differences in their biochemical and physiological activity [23]. People have attempted to further subdivide this type of $M \Phi$, but a way to classify them further has not been developed. When stimulated by IL- 4 and/or IL-13, MФ can develop into alternatively activated (M2a). M2 can be further subdivided into those induced by immune complexes (ICs) and LPS or IL-1b (M2b) or those induced by IL-10, TGF-b, or glucocorticoids (M2c). However, one researcher [24] proposed that M2b and M2c belonged to a subtype of activated macrophages that required two stimuli to induce their antiinflammatory activity. In our experiment, we select M2a as the alternative activated subtype because it is involved in injury repair and has been studied extensively.

Previous studies often have used a fixed-dose stimulus acting for a fixed time to generate activated MФ [25]. Measuring enzyme activity of biomarkers iNOS and arginase 1 can reflect the strength of the biological activity of activated $M \Phi$. Our study suggests that the biological activity of activated $М \Phi$ is different when induced by stimuli at different doses for different times. Therefore, the conditions that produce the optimal activation of $M \Phi$ in vitro must be investigated. The results of our experiments also show that M1 expresses arginase activity that is significantly weaker than that of M2a. Results of a previous study also demonstrated that arginase expression could be triggered by IL-4 and IL10 as well as by detoxified LPS, while IFN $-\gamma$ induced only NO synthesis in macrophages in vitro [26].

In conclusion, our data indicate that the chemotactic ability of MIP-1 $\alpha$ for M2 is significantly stronger than for M1, while the capacity of M1 to produce MIP- $1 \alpha$ is better than that of M2. RPI is a multi-cell and multicytokine-mediated cascading event, many cytokines such as TNF- $\alpha$ may play an important role in the process of RPI [27], but they could not completely explain its pathogenesis. The important roles of macrophages at different stages of RPI and the interactions between macrophages and chemokines may mean that chemokines could be key factors in the pathogenesis of RPI through chemotactic disparity of different cells, or even different subtypes of the same cell. Blocking the expression of MIP- $1 \alpha$ or inhibiting its chemotactic ability could control the degree of repair in vivo, which may be 
a promising method of preventing RPI. Studies are continuing to examine the interactions between different activated MФ and MIP-1 $\alpha$ in an RPI mouse model, and their role in the pathogenesis of RPI.

\section{Acknowledgements}

This study was supported by grants from National Natural Science Foundation of China (NSFC No. 30770653).

\section{Author details}

'Department of Radiation and Medical Oncology, Zhongnan Hospital, Wuhan University, 169, Donghu Road, Wuchang District, Wuhan, Hubei 430071, P.R. China. ${ }^{2}$ Hubei Key Laboratory of Tumor Biological Behaviors, Wuhan University, Wuhan, 169, Donghu Road, Wuchang District, Wuhan, Hubei 430071, P.R. China.

\section{Authors' contributions}

$\mathrm{ZH}$ and $\mathrm{HZ}$ contributed significantly to study design and concept. $\mathrm{ZH}, \mathrm{CY}$ and $Y Z$ (Yajuan Zhou) contributed to manuscript writing and study coordinator. YZ (Yong Zhou) and GH contributed to statistical analysis. LX, WO and FZ contributed significantly to the acquisition of data and optimization of treatment plans. YZ (Yunfeng Zhou) and CX contributed to final revision of manuscript. All authors read and approved the final manuscript.

\section{Competing interests}

The authors declare that they have no competing interests.

Received: 9 February 2011 Accepted: 22 July 2011

Published: 22 July 2011

\section{References}

1. Finkelstein $\mathrm{JN}$, Johnston CJ, Baggs R, Rubin P: Early alterations in extracellular matrix and transforming growth factor beta gene expression in mouse lung indicative of late radiation fibrosis. Int I Radiat Oncol Biol Phys 1994, 28:621-631.

2. Buttner C, Skupin A, Reimann T, Rieber EP, Unteregger G, Geyer P, Frank KH: Local production of interleukin-4 during radiation-induced pneumonitis and pulmonary fibrosis in rats: macrophages as a prominent source of interleukin-4. Am J Respir Cell Mol Biol 1997, 17:315-325.

3. Modolell M, Corraliza IM, Link F, Soler G, Eichmann K: Reciprocal regulation of the nitric oxide synthase/arginase balance in mouse bone marrowderived macrophages by TH1 and TH2 cytokines. Eur J Immunol 1995, 25:1101-4.

4. Johnston CJ, Williams JP, Okunieff P, Finkelstein JN: Radiation-induced pulmonary fibrosis: examination of chemokine and chemokine receptor families. Radiat Res 2002, 157:256-265.

5. Smith RE, Strieter RM, Phan SH, Phan SH, Lukacs NW, Huffnagle GB, Wilke CA, Burdick MD, Lincoln P, Evanoff H, Kunkel SL: Production and function of murine macrophage inflammatory protein-1 alpha in bleomycin-induced lung injury. J Immunol 1994, 153:4704-12.

6. Standiford TJ, Kunkel SL, Liebler JM, Burdick MD, Gilbert AR, Strieter RM: Gene expression of macrophage inflammatory protein-1 alpha from human blood monocytes and alveolar macrophages is inhibited by interleukin-4. Am J Respir Cell Mol Biol 1993, 9:192-198.

7. Berkman N, John M, Roesems G, Jose PJ, Barnes PJ, Chung KF: Inhibition of macrophage inflammatory protein-1 alpha expression by IL-10. Differential sensitivities in human blood monocytes and alveolar macrophages. J Immunol 1995, 155:4412-18.

8. Von Stebut E, Metz M, Milon G, Knop J, Maurer M: Early macrophage influx to sites of cutaneous granuloma formation is dependent on MIP-1alpha/ beta released from neutrophils recruited by mast cell-derived TNFalpha. Blood 2003, 101:210-215.

9. DiPietro LA, Burdick M, Low QE, Kunkel SL, Strieter RM: MIP-1alpha as a critical macrophage chemoattractant in murine wound repair. J Clin Invest 1998, 101:1693-98.

10. Rubin $\mathrm{P}$, Johnston CJ, Williams JP, McDonald S, Finkelstein JN: A perpetual cascade of cytokines postirradiation leads to pulmonary fibrosis. Int $J$ Radiat Oncol Biol Phys 1995, 33:99-109.
11. Green LC, Wagner DA, Glogowski J, Skipper PL, Wishnok JS, Tannenbaum SR: Analysis of nitrate, nitrite, and [15N]nitrate in biological fluids. Anal Biochem 1982, 126:131-138.

12. Corraliza IM, Campo ML, Soler G, Modolell M: Determination of arginase activity in macrophages: a micromethod. J Immunol Methods 1994, 174:231-235.

13. Taub DD, Conlon K, Lloyd AR, Oppenheim JJ, Kelvin DJ: Preferential migration of activated CD4+ and CD8+ T cells in response to MIP-1 alpha and MIP-1 beta. Science 1993, 260:355-358.

14. Schall TJ, Bacon K, Camp RD, Kaspari JW, Goeddel DV: Human macrophage inflammatory protein alpha (MIP-1 alpha) and MIP-1 beta chemokines attract distinct populations of lymphocytes. J Exp Med 1993, 177:1821-26.

15. Proudfoot AE, Power CA, Rommel C, Wells TN: Strategies for chemokine antagonists as therapeutics. Semin Immunol 2003, 15:57-65.

16. Sica A, Saccani A, Borsatti A, Power CA, Wells TN, Luini W, Polentarutti N, Sozzani S, Mantovani A: Bacterial lipopolysaccharide rapidly inhibits expression of C-C chemokine receptors in human monocytes. J Exp Med 1997, 185:969-974

17. Loetscher P, Seitz M, Clark-Lewis I, Baggiolini M, Moser B: Activation of NK cells by CC chemokines. Chemotaxis, Ca2+ mobilization, and enzyme release. J Immunol 1996, 156:322-327.

18. Taub DD, Sayers TJ, Carter CR, Ortaldo JR: Alpha and beta chemokines induce NK cell migration and enhance NK-mediated cytolysis. J Immunol 1995, 155:3877-88.

19. Lukacs NW, Kunkel SL, Allen R, Evanoff HL, Shaklee CL, Sherman JS, Burdick MD, Strieter RM: Stimulus and cell-specific expression of C-X-C and C-C chemokines by pulmonary stromal cell populations. Am J Physiol 1995, 268:L856-861.

20. O'Shea JJ, Murray PJ: Cytokine signaling modules in inflammatory responses. Immunity 2008, 28:477-487.

21. Yamamoto M, Sato S, Hemmi H, Hoshino K, Kaisho T, Sanjo H, Takeuchi O, Sugiyama M, Okabe M, Takeda K, Akira S: Role of adaptor TRIF in the MyD88-independent toll-like receptor signaling pathway. Science 2003, 301:640-643.

22. Nathan C, Xie QW: Nitric oxide synthases: roles, tolls, and controls. Cell 1994, 78:915-918.

23. Edwards JP, Zhang X, Frauwirth KA, Mosser DM: Biochemical and functional characterization of three activated macrophage populations. $J$ Leukoc Biol 2006, 80:1298-1307.

24. Mosser DM, Edwards JP: Exploring the full spectrum of macrophage activation. Nat Rev Immunol 2008, 8:958-969.

25. Zhang B, Wang J, Gao J, Guo Y, Chen X, Wang B, Gao J, Rao Z, Chen Z: Alternatively activated RAW264.7 macrophages enhance tumor lymphangiogenesis in mouse lung adenocarcinoma. J Cell Biochem 2009, 107:134-143.

26. Corraliza IM, Soler G, Eichmann K, Modolell M: Arginase induction by suppressors of nitric oxide synthesis (IL-4, IL-10 and PGE2) in murine bone-marrow-derived macrophages. Biochem Biophys Res Commun 1995, 206:667-673.

27. Hong JH, Junq SM, Tsao TC, Wu CJ, Lee CY, Chen FH, Hsu CH, McBride WH, and Chiang CS: Bronchoalveolar lavage and interstitial cells have different roles in radiation-induced lung injury. Int J Radiat Biol 2003, 79:159-167.

\section{doi:10.1186/1748-717X-6-86}

Cite this article as: He et al:: The interaction between different types of activated RAW 264.7 cells and macrophage inflammatory protein-1 alpha. Radiation Oncology 2011 6:86. 